\title{
Photoreduction of Monoclonal Antibodies for Conjugation and Fragmentation
}

BioTechniques 28:318-326 (February 2000)

\section{David Ellison, Maria A. Stalteri and Stephen J. Mather St. Bartholomew's Hospital, London, England, UK}

\begin{abstract}
The conjugation of enzymes, fluorescent or radioactive labels, cross-linkers and other moieties to antibodies is a commonly performed procedure in biochemical research. Using reduced disulphides, conjugation can be an inconvenient, multistep, time- and material-consuming process. We have developed a reduction technique based on UV irradiation, which lacks these drawbacks. Antibodies are irradiated in a sealed vial for a few minutes by a common laboratory $U V$ source in the presence of stannous ions, following the depletion of atmospheric oxygen. The preparation may subsequently be conjugated with thiol-reactive probes such as maleimide derivatives, with no need for any prior purification or concentration. This simple, rapid and effective reduction and conjugation process results in a fully functional immunoglobulin conjugate that can be used for a variety of biochemical applications.
\end{abstract}

\section{INTRODUCTION}

The conjugation of enzymes, fluorescent or radioactive labels, cross-linkers and other moieties to antibodies is a commonly performed procedure in biochemical research. The epsilon-primary amines of lysine residues are the most common target for such procedures, which necessarily results in a heterogeneous distribution of molecules throughout the immunoglobulin structure. If the most accessible lysines lie within or adjacent to those complementarity-determining regions (CDRs) that define the epitope binding of the antibody, then the conjugation procedure can have a deleterious effect on the immunoreactivity of the resulting conjugate. For this reason, cysteine residues are often considered as an alternative site for conjugation. The most available cysteines are located in the hinge of the antibody molecule, away from their binding sites, and cysteine conjugation is therefore unlikely to have any significant effect on the biological activity of the conjugate.

Unfortunately, almost all the cysteines present in the immunoglobulin are in the oxidized form of disulphide bridges. Before they can participate in nucleophilic reactions with potential marker molecules, they need to be reduced to the free thiol. Such a reduction is normally an inconvenient, multistep, time- and material-consuming process. The antibody, possibly after dialysis, is first reacted with a suitable reducing agent, normally a mono- or dithiol that must then be removed before the conjugation procedure because the low mole- cular-weight thiols will compete with those generated in the antibody in subsequent reactions. Further dialysis or concentration steps may be required before the conjugation step can be performed, all of which require an investment in time and result in greater uses of material. The propensity for the reduced thiols to reoxidize following removal of the reductant can also create difficulties if subsequent steps take a significant length of time. Attempts to overcome some of these disadvantages have included the use of non-thiol reductants such as phosphines (1) or electrochemical methods (3), but they have not achieved wide acceptance.

Photolabeling is a procedure that was initially developed by Sykes et al. (9) for labeling monoclonal antibodies with technetium-99m, a radionuclide with a high affinity for free thiols $(6,9)$. We have adapted this technique, which involves the exposure of the antibody to intermediate wavelength UV radiation, and use it for reduction of immunoglobulin disulphide bridges in the generation of immunoconjugates and preparation of $\mathrm{Fab}^{\prime}$ antibody fragments.

\section{MATERIALS AND METHODS}

The antibody used for these studies was PR1A3, a mouse IgG1 monoclonal that binds to an epitope on cell-associated carcinoembryonic antigen (8). It was produced within the Biotherapeutics Development Unit of Imperial Cancer Research Fund (ICRF, Clare Hall, London, England, UK). F( $\left.a b^{\prime}\right) 2$ fragments of PR- 
1A3 were prepared by conventional pepsin digestion and ion-exchange purification (7). Binding assays were performed using MKN45 (ATCC, Mannasas, VA, USA) a CEA positive human gastric cancer cell line (2). All chemicals were purchased from Sigma (Poole, England, UK) unless otherwise indicated.

\section{UV Source}

The original publications describing the procedure for photolabeling used a dedicated photochemical reactor (Rayonet RMR; Southern New England Ultraviolet, Bradford, CT, USA) with eight UV tubes (6). To see if a more generally available instrument could be used, a standard laboratory transilluminator (UVP, San Gabriel, CA, USA) containing two $300 \mathrm{~nm}$ UV tubes were assessed.

\section{Photoreduction Procedure}

A typical partial photoreduction of intact antibody was performed as follows. Five milliliters of $50 \mathrm{nM}$ PBS, $\mathrm{pH}$ 7.0 , were injected into a $10 \mathrm{~mL}$ nitrogen-filled borosilicate glass vial with a rubber septum. The solution was purged with nitrogen for $15 \mathrm{~min}$. One hundred microliters of $4 \mathrm{mg} / \mathrm{mL}$ PR1A3 antibody in PBS were injected into another $10 \mathrm{~mL}$ vial, and the vial was purged with nitrogen for $15 \mathrm{~min}$. An Amerscan Medronate II kit (Amersham Pharmacia Biotech, Little Chalfont, Buckinghamshire, England, UK) containing $5 \mathrm{mg}$ sodium medronate, $0.34 \mathrm{mg}$ stannous fluoride and $2 \mathrm{mg}$ sodium p-aminobenzoate was reconstituted with $2 \mathrm{~mL}$ of the nitrogen-purged PBS. One hundred microliters of this medronate solution was injected into the vial containing the antibody, and the vial was irradiated for $30 \mathrm{~min}, 2 \mathrm{~cm}$ away from the exposed UV tubes of the transilluminator.

Quantitative reduction of the $F\left(a^{\prime}\right) 2$ fragments to Fab' required more stringent conditions. Typically, $200 \mu \mathrm{g}(200$ $\mu \mathrm{L})$ of PR1A3 F(ab')2, $80 \mu \mathrm{g}(100 \mu \mathrm{L})$ of p-aminobenzoic acid and $50 \mu \mathrm{g}(10$ $\mu \mathrm{L})$ stannous fluoride, all in $0.1 \mathrm{M}$ phosphate buffer $\mathrm{pH}, 7.0$, containing 0.05 $\mathrm{mM}$ EDTA were injected into a $10 \mathrm{~mL}$ nitrogen-filled borosilicate glass vial with a rubber septum and the solution purged with nitrogen for $15 \mathrm{~min}$ before

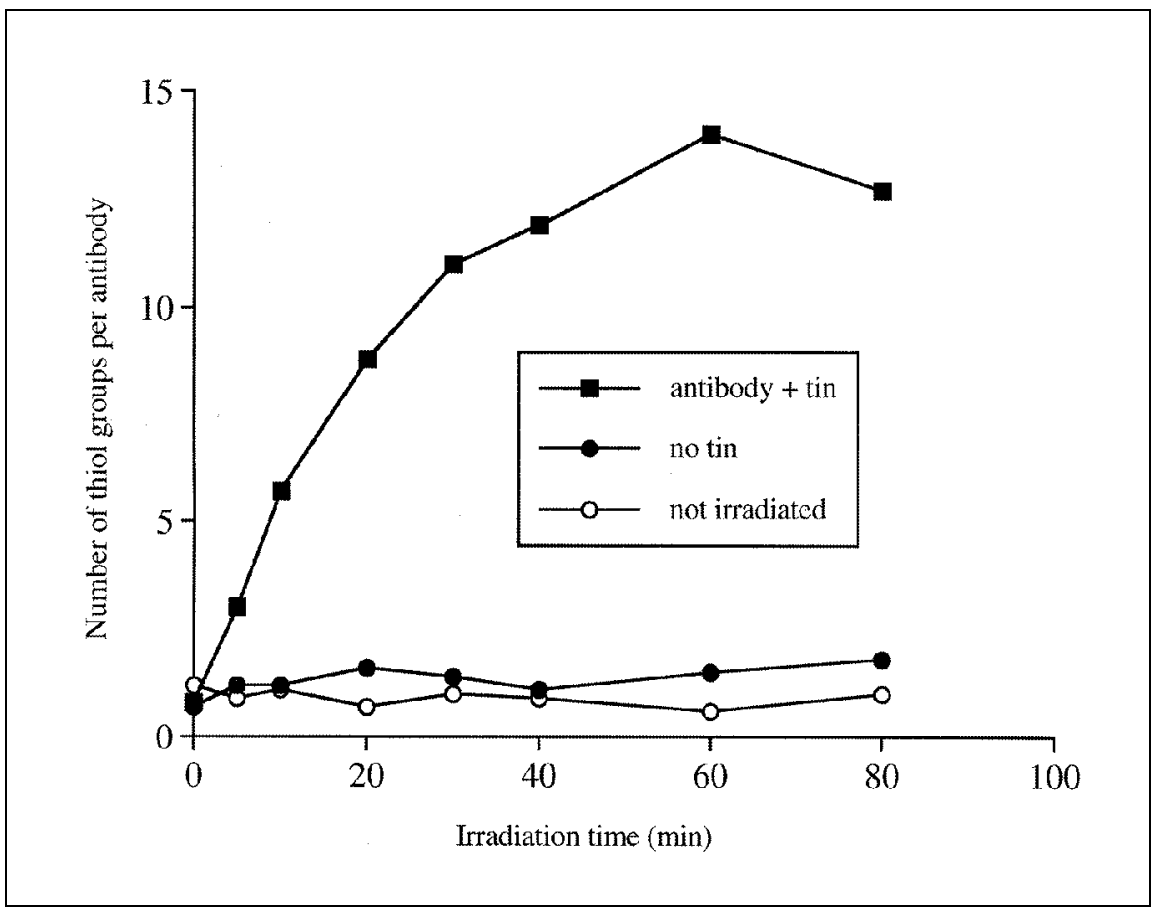

Figure 1. Effect of irradiation time on generation of free thiols in the antibody. Antibodies were irradiated for up to $80 \mathrm{~min}$ in the presence of stannous ions. Free thiol concentration was measured by Ellman's assay and compared with the levels present in non-irradiated antibody and antibody irradiated in the absence of tin. 
photoreduction for $40 \mathrm{~min}$ on the transilluminator. The reduced preparations were stored at $-20^{\circ} \mathrm{C}$ until required.

\section{Conjugation}

Biotinylation was used to assess the conjugation procedure. Twenty microliters of a freshly prepared $1 \mathrm{mg} / \mathrm{mL}$ solution of N-biotinoyl-N'-(6-maleimidohexanoyl)-hydrazide (biotin maleimide) in DMF were added rapidly by stirring to $0.5 \mathrm{~mL}$ of a $2 \mathrm{mg} / \mathrm{mL}$ solution of photoreduced PR1A3 in $50 \mathrm{mM}$ PBS. The mixture was incubated on ice for $2 \mathrm{~h}$ and then purified using a PD-10 column (Amersham Pharmacia Biotech) eluted with $0.1 \mathrm{M}$ phosphate buffer $\mathrm{pH}$ 7.0.

\section{Thiol Assay}

The number of free thiols per antibody produced during irradiation was measured using Ellman's reagent,

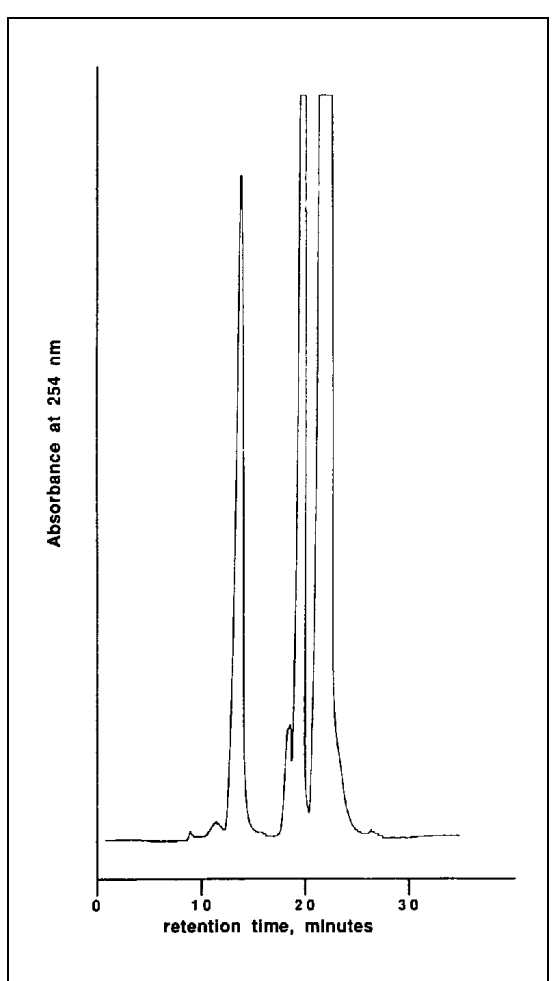

Figure 2. Size-exclusion HPLC analysis of photoreduced antibody. The chromatogram shows a single sharp peak (retention time 13.7 min) indicating the lack of any fragmentation of the antibody under non-denaturing conditions. Peaks at 19.5 and $21.5 \mathrm{~min}$ are attributable to the buffer salts and to p-aminobenzoate (reprinted from Reference 6 with permission).
DTNB. Then, $100 \mu \mathrm{L}$ aliquots of the sample were added to $900 \mu \mathrm{L}$ of $0.1 \mathrm{M}$ sodium phosphate buffer, $\mathrm{pH}$ 7.0. Next, $1 \mathrm{~mL}$ of $0.2 \mathrm{mg} / \mathrm{mL}$ DTNB in $0.1 \mathrm{M}$ phosphate, $\mathrm{pH}$ 7.0, was added, and the solutions were mixed and incubated at room temperature for $20 \mathrm{~min}$. The absorbance at $412 \mathrm{~nm}$ using a CE 272 UV/vis spectrophotometer (Cecil Instruments Ltd., Cambridge, England, UK) was then measured against that of $0.1 \mathrm{M}$ phosphate, $\mathrm{pH} 7.0$, which was used as the spectrophotometer blank. A standard curve was constructed using a series of 8 cysteine standards ranging from $0-0.2 \mathrm{mM}$ cysteine in $0.1 \mathrm{M}$ phosphate, $\mathrm{pH}$ 7.0. The experimentally determined value of the molar extinction coefficient at $412 \mathrm{~nm}$ was then used to calculate the thiol concentration of the antibody samples and the number of thiols per antibody.

\section{HPLC}

Size exclusion HPLC analysis was performed using a Beckman $114 \mathrm{M}$ pump with a $160 \mathrm{UV}$ detector (both from Beckman Coulter, High Wycombe, England, UK) at $254 \mathrm{~nm}$ connected to a SP4290 integrator (SpectraPhysics, San Jose, CA, USA). A column (SEC 3000, Beckman Coulter), with op- timal separation range 5-700 kDa, a 2.0 $\mathrm{mL}$ injection loop and a flow rate of 0.5 $\mathrm{mL}$ per min, were used. The mobile phase used was $0.2 \mathrm{M}$ sodium phosphate, $\mathrm{pH}$ 7.0, 2 mM EDTA.

\section{Radiolabeling}

The photoreduced antibody that was prepared using the procedure for partial reduction of intact antibody was radiolabeled by the addition to $100 \mu \mathrm{g}$ of antibody of $74 \mathrm{MBq}$ of sodium [99m-Tc] pertechnetate eluted from a $99-\mathrm{Mo} /$ 99m-Tc radionuclide generator (Amersham Pharmacia Biotech) and incubated at room temperature for $30 \mathrm{~min}$. The radiochemical purity of the labeled preparations was measured by HPLC and instant thin layer chromatography (ITLC) methods as previously described (7) and in all instances exceeded $95 \%$.

\section{Radioligand Binding Assays}

The immunoreactive fraction of 99m-technetium-labeled, photoreduced antibody was measured by radioimmunoassay using a method similar to that of Lindmo et al. (4) as described previously (6). Briefly, $250 \mu \mathrm{L}$ of a solution of $50 \mathrm{ng} / \mathrm{mL} 99 \mathrm{~m}$-technetiumlabeled PR1A3 were added to $500 \mu \mathrm{L}$

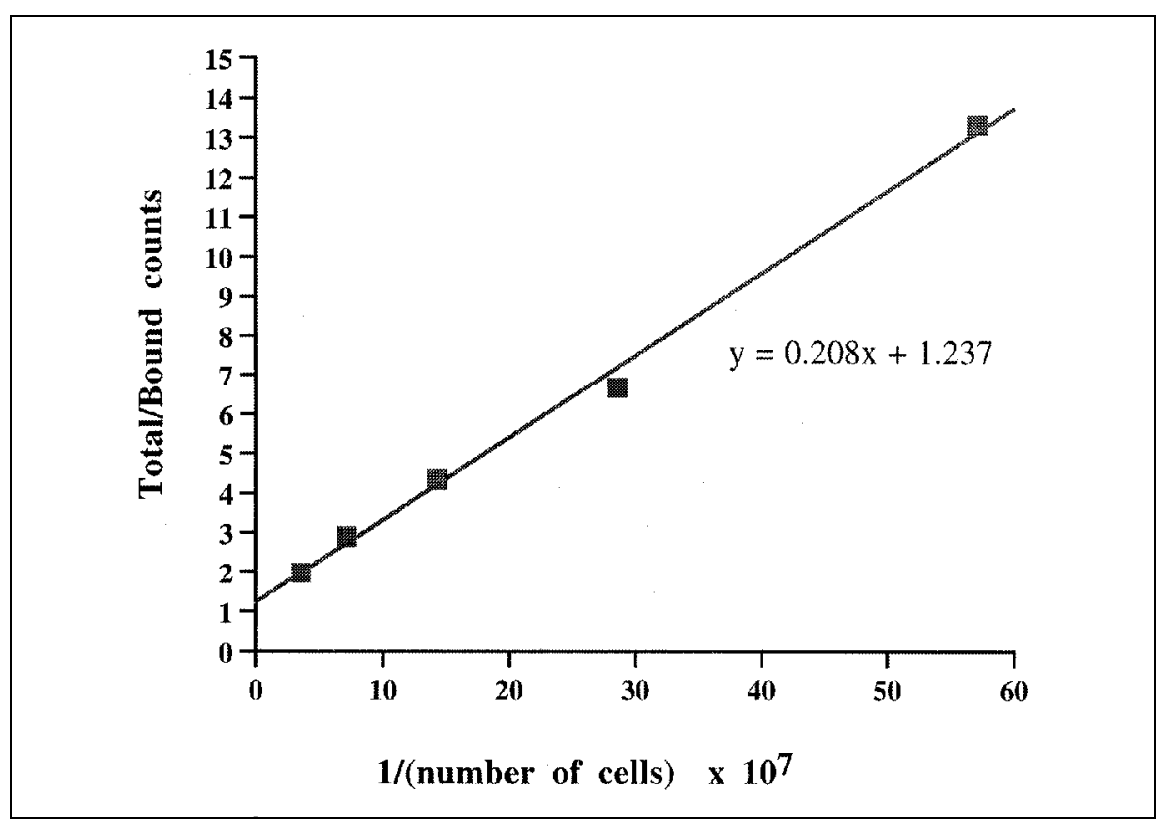

Figure 3. Measurement of immunoreactive fraction of 99m-technetium-labeled, photoreduced antibody. Line-Burkeweaver plot of binding of the radiolabeled antibody to CEA-positive MKN45 cells. The reciprocal of the intercept on the y-axis (1.237) indicates an immunoreactive fraction of $81 \%$. 
of a cell suspension of MKN-45 cells at five concentrations ranging from 2$0.125 \times 10^{6}$ per $\mathrm{mL}$. The tubes were incubated at room temperature for $2 \mathrm{~h}$ with continuous rotation. Thereafter, the cells were centrifuged for $1 \mathrm{~min}$ at 160 $g$, the supernatant removed and the cell pellets washed twice with $0.5 \mathrm{~mL}$ of cold $50 \mathrm{mM}$ PBS, $\mathrm{pH} 7.0$, containing $1 \%$ human serum albumin. The cell pellets were counted in a gamma counter (Ultragamma 1282; LKB/Wallac, Tur$\mathrm{ku}$, Finland). Nonspecific binding was measured by co-incubation with $200 \mu \mathrm{g}$ of unlabeled PR1A3. The data were analyzed by plotting the reciprocal of the proportion of counts bound against the reciprocal of the cell concentration. The reciprocal of the intercept on the $y$-axis at $\mathrm{x}=0$ gives a measure of the binding at a theoretical point of infinite cell concentration, which is known as the immunoreactive fraction.

The affinity of the 99m-technetiumlabeled PR1A3 Fab' was measured us-

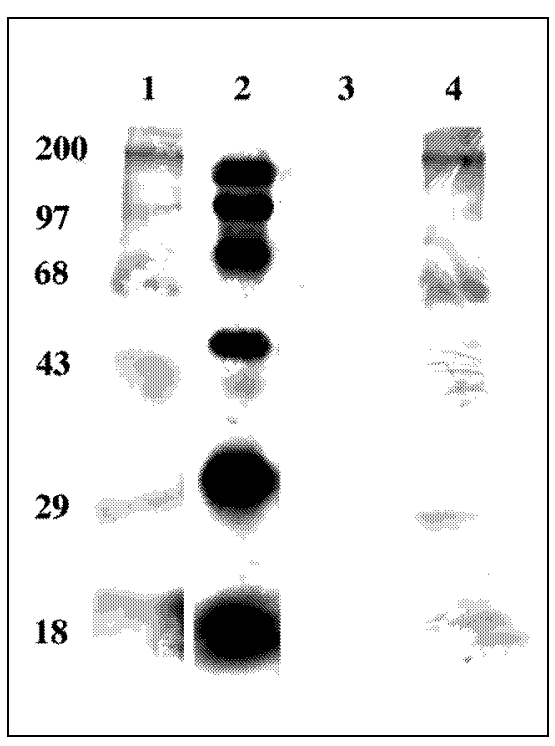

Figure 4. Digitized blot of biotinylated antibody conjugates. The antibody preparations were analyzed by nonreducing SDS-PAGE, electrophoretically transferred to nitrocellulose and probed with avidin-alkaline phosphatase. The blot shows that all combinations of reduced heavy chain and light chain are present in the denatured preparation (lane 2). Thiols in all bands have been biotinylated and show binding to alkaline-phosphatase conjugated avidin through the generation of stained bands. Lane 3 carries a nonirradiated antibody that shows no reduction and consequently, no biotinylation and staining. Lanes 1 and 4 show electrophoretic transfer of pre-stained molecular weight markers with molecular weights in $\mathrm{kDa}$. ing a conventional binding assay. Eight serial 1 in 2 dilutions were prepared from a stock solution of $30 \mu \mathrm{g} / \mathrm{mL}$ $99 \mathrm{~m}$-Technetium labeled $\mathrm{Fab}^{\prime}$ in 50 $\mathrm{mM}$ PBS, pH 7.0, containing $1 \%$ human serum albumin. Then, $250 \mu \mathrm{L}$ of each dilution were incubated in $2 \mathrm{~mL}$ microcentrifuge tubes with $1 \times 10^{6}$ MKN-45 cells in the same solvent for 3 $\mathrm{h}$ at $20^{\circ} \mathrm{C}$. An identical series of incubations were performed with the addition of $165 \mu \mathrm{g}$ of PR1A3 antibody to assess nonspecific binding. After the incubation period, the tubes were centrifuged for $1 \mathrm{~min}$ at $160 \mathrm{~g}$, the supernatant was removed and the cell pellets were washed twice with $0.5 \mathrm{~mL}$ of cold $50 \mathrm{mM}$ PBS, pH 7.0, containing 1\% human serum albumin. The supernatants and washings were combined and counted together with the cell pellets in a gamma counter. The data were analyzed by nonlinear regression using Origin Software (Microcal Software, Northampton, MA, USA).

\section{SDS-PAGE and Blotting}

Antibody preparations were analyzed by SDS-PAGE using $8 \times 10 \mathrm{~cm}$ isocratic gels (Mini Slab kit; Atto, Tokyo, Japan) run under nonreducing conditions. We used 3\%/10\% acrylamide gels for $\mathrm{Fab}^{\prime}$ preparations and $3 \% / 7.5 \%$ for antibody conjugates. Blotting was performed after transfer overnight at $50 \mathrm{~V}$ to nitrocellulose in 0.025 M Tris-0.192 M glycine, $\mathrm{pH} 8.5$, containing $20 \%$ methanol. After blocking with $0.05 \%$ Tween $^{\circledR} 20 / \mathrm{PBS}$, the blot was incubated with alkaline phosphatase-conjugated-avidin (A-7294; Sigma) 1 in 1000 in $0.05 \%$ Tween 20/PBS for $1 \mathrm{~h}$, washed three times for 30 min and visualized using BCP/NBT solution (B-6404; Sigma).

\section{RESULTS}

\section{Antibody Conjugation}

The preliminary experiment showed that the exclusion of oxygen from the photoreduction container was essential for efficient reduction. Figure 1 shows the effect of increasing irradiation times on the generation of thiols in the intact IgG form of the monoclonal antibody PR1A3. An increase in the num-

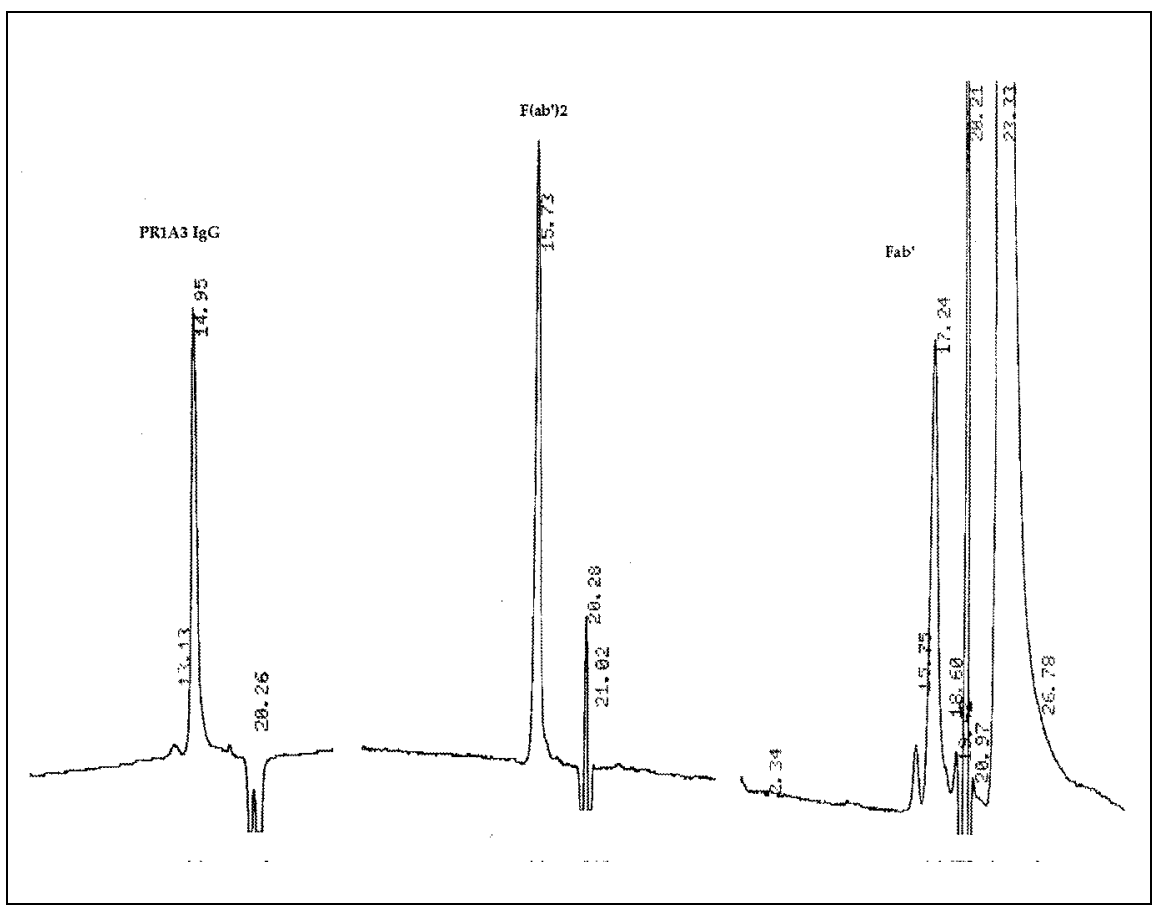

Figure 5. Size-exclusion HPLC analysis of antibody, $F\left(a^{\prime}\right) 2$, and photoreduced $F_{a b}$ fragments. UV chromatograms of the three antibody preparations are combined in one figure. The retention times of intact antibody, $\mathrm{F}\left(\mathrm{ab}^{\prime}\right) 2$ and $\mathrm{Fab}^{\prime}$ are 14.95, 15.73 and 17.24 min, respectively. The Fab' sample shows a small percentage ( $9 \%$ in this example) of nonreduced $\mathrm{F}\left(\mathrm{ab}^{\prime}\right) 2$. 
ber of thiols generated, up to a maximum of an average of 14 thiols per immunoglobulin molecule from a theoretical total of 34 , was seen with up to 60 min irradiation with a decline thereafter. Figure 1 also shows that a combination of the presence of the weak reducing agent stannous ion and UV irradiation are required for disulphide cleavage. Neither agent on its own results in any reduction.

Other studies (data not shown) have demonstrated that the presence of the antioxidant p-aminobenzoic acid significantly enhances the reduction process. Size-exclusion HPLC analysis of the photoreduced antibody shows a single peak with characteristics identical to those of the untreated antibody (Figure 2). As shown in Figure 3, the photoreduction process does not appear to have a deleterious effect upon the binding of the antibody. The technetium-labeled antibody showed an immunoreactive fraction of about $80 \%$ when tested in a direct radioimmunoassay. A subsequent conjugation reaction was tested using maleimido-biotin because biotinylated antibodies are commonly used probes and maleimide is the most frequently used reactive group for attachment to thiols. The conjugation was performed without any purification of the photoreduced antibody, that is, in the same buffer and in the

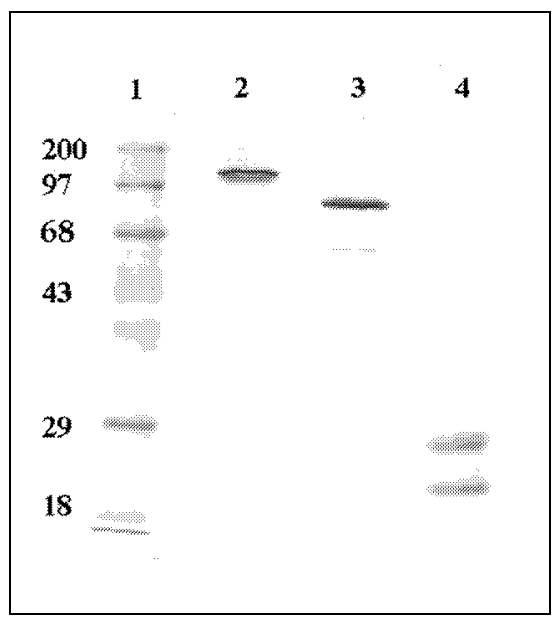

Figure 6. Digitized Coomassie blue stained nonreducing SDS-PAGE of antibody, $F\left(a^{\prime}\right) 2$, and

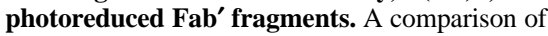
lanes 3 and 4 shows the efficiency of the UV irradiation in reducing $F\left(a b^{\prime}\right) 2$ fragments to Fab'. Only a small proportion of nonreduced material remains. Lane 2 contains a nonreduced antibody. presence of residual concentrations of stannous fluoride and p-ABA. After purification by PD-10 to remove unreacted maleimido-biotin, the PR1A3-biotin conjugate was analyzed by SDSPAGE. The separated components were then electrophoretically transferred to nitrocellulose and probed by reaction with avidin-alkaline phosphatase. The blot (Figure 4) shows several streptavidin-reactive proteins that correspond to various possible combinations of heavy and light chains that are separated under the denaturing conditions of the SDS-PAGE, specifically intact IgG (ca. $150 \mathrm{kDa}$ ), H-H (ca. 100), H-L (ca. 75), H (ca. 50) and L (ca. 25).

\section{Fab' Preparation}

$\mathrm{Fab}^{\prime}$ fragments are useful immunological reagents with both in vitro and in vivo applications. These proteins may be used either in their native state, conjugated to marker molecules or covalently cross-linked to form homo- or heterodimers with increased stability. The thiol groups that were generated as a result of the reductive cleavage of the $\mathrm{F}\left(a b^{\prime}\right) 2$ to the $\mathrm{Fab}^{\prime}$ again form a useful target for such conjugation chemistry, so photoreduction was explored as a possible means of generating such fragments.

The $F\left(a b^{\prime}\right) 2$ fragments of PR1A3 were prepared by conventional pepsin digestion as previously described (7). Initial experimentation showed that the irradiation conditions used for antibody conjugation generated only a few percent of Fab'. However, an increase in the amount of stannous ion increased the efficiency to acceptable levels so that using $200 \mu \mathrm{g}$ of tin, with yields of $90 \%$, were achieved and can be seen in the HPLC traces shown in Figure 5. Under the denaturing condition of SDSPAGE, the Fab' resolves into bands corresponding to the residual heavy chain and light chain as shown in Figure 6.

The Fab' fragments were generated by photoreduction radiolabel efficiently $(>95 \%)$ with the addition of sodium [99m-Tc]pertechnetate. The binding affinity of the labeled fragments was studied in a radioligand binding assay. Scatchard analysis of the binding data showed that the binding could not be explained by single-site binding, and therefore the data were analyzed using a nonlinear regression approach that fit

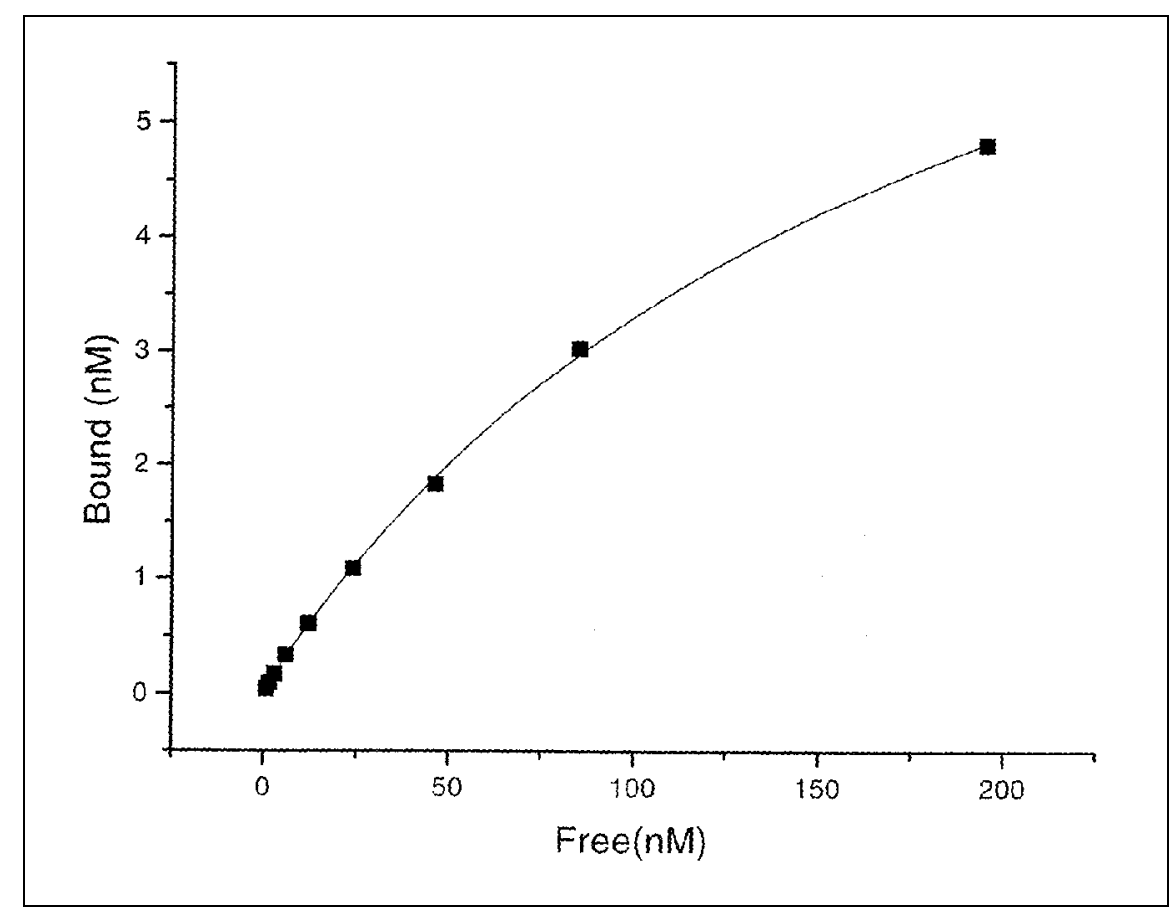

Figure 7. Radioligand binding assay of 99m-technetium-Fab'. A curve was fitted to binding data obtained in a radioligand binding assay of 99m-technetium labeled Fab' to CEA-positive MKN45 cells by nonlinear regression. The results indicate a low-capacity, high-affinity binding site with an association constant of $0.8 \mathrm{nM}$ and a high-capacity, moderate-affinity site with an association constant of $185 \mathrm{nM}$. 
the binding data satisfactorily to a twosite model using the equation ( $\mathrm{y}=$ $\left(\mathrm{B}_{1} \cdot \mathrm{x} /\left(\mathrm{K}_{1}+\mathrm{x}\right)=\mathrm{B}_{2} \cdot \mathrm{x} /(\mathrm{K} 2+\mathrm{x})\right)$ as shown in Figure 7. The results indicate a lower-capacity, high-affinity binding site with an association constant of 0.8 $\mathrm{nM}$ and a higher-capacity, moderateaffinity site with an association constant of $185 \mathrm{nM}$. This compares with binding constants of 1 and $166 \mathrm{nM}$, respectively, previously determined for the intact antibody (8).

\section{DISCUSSION}

This photoreduction represents a simple and effective means of reducing the disulphide bridges in immunoglobulin molecules before conjugation or other chemical derivatization procedures. Although not yet explored, it seems likely that the technique would be applicable to other disulphidebridged polypeptides. The precise mechanism of the reduction remains unclear. It is apparent that the presence of both stannous ion and UV irradiation are essential for disulphide reduction because on their own (in the concentrations used here), neither of the two agents is effective. It seems likely that the UV irradiation results in the formation of a labile intermediate that is then stabilized by the stannous ions using the formation of reversible coordination complexes in a manner analogous to the pre-tinning approach of Rhodes (5).

The role of oxygen is also crucial. We found that extensive purging of solutions and containers with nitrogen to remove air was essential for reduction, presumably because the presence of oxygen promotes reoxidation of the intermediate. We found that the presence of an antioxidant p-aminobenzoic acid, while not essential, greatly improved the efficiency of the reduction, although whether due to a direct or indirect effect was not clear. While we had used previously a dedicated UV photochemical reactor for the photoreduction, we found that a conventional laboratory transilluminator, similar to that used in many laboratories for visualization of DNA in gels, was equally effective for this purpose.

The extent of reduction depended on the time of irradiation. We found that irradiation under our standard conditions for one hour generated a maximum number of free thiols of about 14 per antibody molecule, as determined using a conventional Ellman's assay. Western blotting of the denatured antibody preparations showed that these thiols were distributed throughout the constituent protein chains of the immunoglobulin. Being able to control 
the extent of reduction by varying the time of irradiation is a useful feature of this technique. Since it is normally desired to elicit a low substitution ratio of whatever marker compound is being used, then only short irradiation times would be needed. However, even extended irradiation times did not appear to influence significantly the structural or functional characteristics of the molecule. Size-exclusion HPLC analysis of the antibody failed to demonstrate any aggregation or fragmentation under non-denaturing conditions, and a direct binding assay of antibody that was radiolabeled using the reduced thiols demonstrated an immunoreactivity approaching $100 \%$.

The possibility that UV irradiation may have additional effects on amino acid side chains other than cysteine cannot be ruled out, although this is more likely at lower wavelengths and higher intensities that those used here. However, the retention of the structural and functional integrity of the antibodies following irradiation, combined with the fact that the biodistribution of radiolabeled antibodies following reduction by either UV irradiation or chemical (mercaptoethanol) reduction, has been shown to be almost identical (7) suggests that these effects are not significant.

The vehicle used for the reduction did not interfere with the subsequent conjugation procedure and no concentration, dialysis or purification steps were required before those used for removal of excess biotin-maleimide. This is in contradistinction to the use of thiolbased reductants that compete for the maleimide reagent and means that losses of material are kept to a minimum. We have determined that reduced antibody preparations, when stored at $-70^{\circ} \mathrm{C}$ in the presence of stannous ions, remain at least partially reduced for more than three months. Thus, reoxidation of free thiols, which can occur quickly after removal of thiol-based reductants, is not a problem with this technique.

Previously, we studied the effects of covalent cross-linking of antibody fragments on their in vivo stability and have shown that such molecules may be more effective in tumor targeting (7). A difficulty we experienced in this work was the poor yield of the cross-linked compounds, as a result of losses experienced during the multistage preparation. Therefore, we were interested to see if photoreduction might be used to generate Fab' fragments for use in such procedures. We found that more stringent reduction conditions (in particular, a high concentration of stannous ions) were necessary to quantitatively reduce the hinge disulphides. However, even such conditions appear to have no untoward effect on the characteristics of the Fab' fragment that also eluted as a single peak on HPLC analysis and in a radioligand binding assay, it demonstrated a binding affinity quite similar to that of the intact immunoglobulin. It seems likely, then, that photoreduction would be an appropriate reduction technique for use in such cross-linking studies, and this will be further explored.

\section{CONCLUSION}

Photoreduction is a simple and rapid technique that can be used for the reduction of disulphide bridges through the use of readily available reagents and laboratory equipment. It causes minimal loss of materials and produces a fully functional molecule that is suitable for use in a variety of subsequent biochemical and immunological procedures.

\section{ACKNOWLEDGMENTS}

The authors gratefully acknowledge the financial support of the Imperial Cancer Research Fund and the facilities of the Dominion House Centre for Clinical Research.

\section{REFERENCES}

1.Chin, C. and F. Wold. 1993. The use of tributylphosphine and 4-(aminosulfonyl)-7-fluoro-2,1,3-benzoxadiazole in the study of protein sulfhydryls and disulfides. Anal. Biochem. 214:128-134.

2.Hojo, H. 1977. Establishment of cultured cell lines of human stomach cancer origin and their morphological characteristics. Niigata Igakukai Zassi 91:737-763.

3.Kadin, H. 1987. Electrochemical reduction of disulphides. Methods Enzymol. 143:257-264.

4.Lindmo, T., E. Boven and F. Cuttita. 1984. Determination of the immunoreactive fraction of radiolabelled monoclonal antibody by linear extrapolation to binding at infinite antigen excess. J. Immunol. Methods 27:77-89.

5.Rhodes, B.A. 1991. Direct labeling of proteins with 99m-Tc. Nucl. Med. Biol. 18:667-677.

6.Stalteri, A. and S. Mather. 1996. Technetium$99 \mathrm{~m}$ labelling of the anti-tumour antibody PR1A3 by photoactivation. Eur. J. Nucl. Med. 23:178-187.

7.Stalteri, M. and S. Mather. 1995. A crosslinked monoclonal antibody fragment for improved tumour targetting. Bioconjug. Chem. 6:179-186.

8.Stewart, L., S. Young, G. Watson, S. Mather, P. Bates, H. Band, R. Wilkinson, E. Ross and D. Snary. 1999. Humanisation and characterisation of PR1A3, a monoclonal antibody specific for cell-bound carcinoembryonic antigen. Cancer Immunol. Immunother. 47:299306.

9.Sykes, T.R., T.K. Woo, R.P. Baum, P. Qi and A.A. Noujaim. 1995. Direct labeling of monoclonal antibodies with technetium-99m by photoactivation. J. Nucl. Med. 36:1913-22.

Received 17 June 1999; accepted 9 September 1999.

Address correspondence to:

Dr. Stephen J. Mather Dept. Nuclear Medicine

St. Bartholomew's Hospital

London ECIA 7BE, England, UK

Internet: mather@icrf.icnet.uk 